Relations industrielles

Industrial Relations

\title{
Réadaptation au travail
}

Volume 1, numéro 3, novembre 1945

URI : https://id.erudit.org/iderudit/1023909ar

DOI : https://doi.org/10.7202/1023909ar

Aller au sommaire du numéro

Éditeur(s)

Département des relations industrielles de l’Université Laval

ISSN

0034-379X (imprimé)

1703-8138 (numérique)

Découvrir la revue

Citer cet article

(1945). Réadaptation au travail. Relations industrielles / Industrial Relations,

1(3), 4-4. https://doi.org/10.7202/1023909ar

Tous droits réservés @ C Département des relations industrielles de l’Université Laval, 1945
Ce document est protégé par la loi sur le droit d'auteur. L'utilisation des services d'Érudit (y compris la reproduction) est assujettie à sa politique d'utilisation que vous pouvez consulter en ligne.

https://apropos.erudit.org/fr/usagers/politique-dutilisation/ 


\section{RÉADAPTATION AU TRAVAIL}

L'expérience des handicapés qui ont travaillé dans les usines de guerre laisse entrevoir des possibilités encourageantes pour les mutilés de la guerre ou pour les victimes d'accidents de travail. En effet, il est maintenant prouvé qu'une incapacité partielle permanente n'est pas un handicap insurmontable sur le marché du travail. C'est la conclusion qui se dégage d'une enquête conduite par le "Bureau of Labor Statistics " (Etats-Unis), en collaboration avec d'autres commissions gouvernementales (1). On a défini le travailleur handicapé comme suit : " un ouvrier marqué de déficiences physiques qui limitent sa capacité de travail s'il ne remplit pas une tâche appropriée ". Or, l'enquête a révélé qu'au point de vue du rendement, de l'absentéisme, de la fréquence accidentelle et du mouvement de la main-d' cuvre, le rendement des tra vailleurs handicapés se compare avantageusement, lorsqu'il n'est pas légèrement supérieur.

Devant ces faits, on ne peut qu'apprécier favorablement l'initiative du ministère du Travail de la province de Québec d'organiser, par l'intermédiaire de la Commission des accidents du travail, une clinique médicale et un service de réhabilitation. Aujourd'hui, la Commission ne s'occupe plus seulement de faire traiter les ouvriers blessés et de leur payer des prestations; grâce à ses nouveaux services, les travailleurs frappés d'incapacité partielle permanente peuvent retrouver une certaine dextérité qui leur permettra de se replacer avantageusement dans les entreprises. De plus, le service de réhabilitation entre en contact avec les employeurs en vue de trouver des emplois appropriés aux travailleurs dont la capacité de travail a été diminuée. C'est là une œuvre sociale par excellence.

Prévention, compensation, réadaptation : voilà les cadres d'un système complet. La province de Québec possède maintenant un tel système. Il reste aux employeurs et aux associations ouvrières de seconder les efforts de la Commission des accidents du travail.

(1) Monthly Labor Review, octobre 1944.

\section{CLAUSES DE RETENUE ...}

\section{(Suite de la page 2)}

Enfin, pour ce qui est des frais de perception, si l'employeur ne veut point les absorber, on peut ajouter aux clauses $a$ ) et $b$ ) la clause $c$ ) suivante :

c) Afin de se dédommager des frais encourus par la retenue syndicale, l'employeur se réserve le droit de charger au compte du syndicat... (généralement $1 / 2$ de $1 \%$ ) ... des sommes qu'il aura ainsi perçues en sa faveur.

Nous avons l'intention de faire, un peu plus tard, l'étude des autres principales clauses de sécurité syndicale : le maintien de l'affiliation syndicale, l'atelier syndical, la préférence syndicale, etc ...

\section{Gérard Dion.}

\section{SYNDICALISME ET ACTION POLITIQUE}

Les syndicats ouvriers ayant pour mission principale de défendre les droits des travailleurs, on conçoit qu'ils veuillent exercer leur influence dans tous les domaines où ils les croient en jeu. Aussi, ils ne limitent pas leur action à la seule amélioration des salaires et conditions de travail par le truchement des conventions collectives ; ils représentent également l'ensemble de la classe ouvrière auprès des autorités gouvernementales. C'est pourquoi ils ne manquent jamais une occasion de faire connaître l'opinion de leurs membres sur les questions politiques, économiques et sociales de l'heure. D'où aussi la difficulté pour eux de délimiter leur champ d'action, de déterminer où finit l'action syndicale et où commence l'action politique. Rappelons d'abord que les associations ouvrières semblent opposées à l'organisation d'un parti politique syndical. Au Canada aussi bien qu'aux Etats-Unis, toutes les tentatives faites dans ce sens ont échoué lamentablement. Cependant, les unions ouvrières ont élaboré, il y a quelques années, une formule originale: celle des comités d'action politique ${ }^{(1)}$.

Le comité d'action politique se consacre avant tout à l'éducation de ses membres. A l'occasion des campagnes électorales, le comité a pour mission de scruter les programmes des partis politiques en vue de bien s'assurer que ceux-ci n'entrent pas en conflit avec les principes des syndicats. Le comité profite encore des périodes électorales pour exposer sa doctrine et faire apprécier le rôle du syndicalisme dans la vie nationale. Un candidat qui serait manifestement opposé au syndicalisme et à la législation ouvrière subirait inévitablement le boycottage du comité d'action politique de sa circonscription.

En principe, il s'agit beaucoup plus d'intéresser les travailleurs à l'action politique que de les inciter à militer officiellement pour un parti politique spécifique. Les membres des syndicats sont invités à se rallier aux candidats, à quelque parti qu'ils appartiennent, qui sont disposés à promouvoir l'application des principes économiques et sociaux du syndicalisme. Mais en pratique, il semble difficile à un comité d'action politique d'éviter le danger d'affiliation directe à un parti politique, ce qui ne va pas sans créer de graves problèmes.

Au Canada, la Confédération des travailleurs catholiques s'oppose formellement à toute modalité d'action politique de la part de ses syndicats affiliés; par contre, le Congrès canadien du Travail et le Congrès des Métiers et du Travail ont fait leur cette formule d'action politique inspirée du C. I. 0 . 